\title{
Modeling and Characteristics Analysis for a Buck-Boost Converter in Pseudo-Continuous Conduction Mode Based on Fractional Calculus
}

\author{
Ningning Yang, ${ }^{1,2}$ Chaojun $W u,{ }^{3}$ Rong Jia, ${ }^{1,2}$ and Chongxin Liu ${ }^{4}$ \\ ${ }^{1}$ State Key Laboratory Base of Eco-Hydraulic Engineering in Arid Area, Xian University of Technology, Xian 710048, China \\ ${ }^{2}$ Institute of Water Resources and Hydro-Electric Engineering, Xian University of Technology, Xian 710048, China \\ ${ }^{3}$ College of Electronics and Information, Xian Polytechnic University, Xian 710048, China \\ ${ }^{4}$ School of Electrical Engineering, Xian Jiaotong University, Xian 710049, China
}

Correspondence should be addressed to Chaojun Wu; chaojun.wu@stu.xjtu.edu.cn

Received 31 October 2015; Revised 9 January 2016; Accepted 14 January 2016

Academic Editor: Luis J. Yebra

Copyright (c) 2016 Ningning Yang et al. This is an open access article distributed under the Creative Commons Attribution License, which permits unrestricted use, distribution, and reproduction in any medium, provided the original work is properly cited.

\begin{abstract}
In recent days, fractional calculus (FC) has been accepted as a novel modeling tool that can extend the descriptive power of the traditional calculus. Fractional-order descriptiveness can increase the flexibility and degrees of freedom of the model by means of fractional parameters. Based on the fact that real capacitors and inductors are "intrinsic" fractional order, fractional calculus is introduced into the modeling process to establish a fractional-order state-space averaging model of the Buck-Boost converter in pseudo-continuous conduction mode (PCCM). Orders of the model are considered as extra parameters, and these parameters have significant influences on the performance of the model. The inductor current, the inductor current ripple, the amplitude of the output voltage, and the transfer functions of the fractional-order model are all related to orders. The contrast simulation experiments are conducted to investigate the performance of integer-order and fractional-order Buck-Boost converters in PCCM. Results of numerical and circuit simulations demonstrate that the proposed theoretical analysis is effective; the fractional-order model of the Buck-Boost converter in PCCM has certain theoretical and practical significance for modeling and performance analysis of other electrical or electronic equipment.
\end{abstract}

\section{Introduction}

Fractional calculus is an old mathematical topic which can go back to 1695; when L'Hospital wrote to Leibniz, he mentioned this kind of calculation [1,2]. Over the past 300 years, several mathematicians contributed to this mathematical subject. In recent years, fractional calculus has been accepted as a new instrument that can extend the descriptive power of the traditional calculus. It has turned out that many phenomena in widespread fields of science and engineering can be described very successfully by fractional-order models [3-9]. Comparing with integer-order models, the significant advantage of fractional-order models is that they are characterized by hereditary and memory properties. And it has been demonstrated that fractional-order models can increase the flexibility and degrees of freedom by means of fractionalorder parameters [10-12].

The theory and applications of fractional-order components had a considerable progress during the last two decades. Researchers have reported the "intrinsic" fractional-order behavior of real objects, such as capacitors and inductors. Westerlund and his colleagues constructed the fractionalorder model of the capacitor and measured the orders of some real capacitors under different dielectrics by experiment $[13,14]$. Westerlund also demonstrated that real inductors are fractional order and measured the orders of some real inductors [14]. Using different fractal structures, fractionalorder capacitors with different orders were implemented by Jesus and Machado [3]. Based on skin effect, Machado and Galhano proposed that fractional-order inductors with 
different orders can be constructed [15]. Real fractional-order capacitors were created by Haba and his colleagues [16, 17]. These realizations of fractional-order capacitors and inductors indicate the possibility of fractional-order components and models being employed in practical applications.

Capacitors and inductors are the fundamental part of the Buck-Boost converter. Based on the facts that real capacitors and inductors are all fractional-order components, the idea of establishing the fractional-order model of the Buck-Boost converter seems to be far more sensible. It can be proved that the order of the model has significant influence on the performance of the Buck-Boost converter and can be considered as an extra parameter. Up to date, few fractionalorder models of converter have been established [18, 19]. Martinez and his colleagues established the fractional-order model of the Buck-Boost converter, but only the capacitor was considered as the fractional-order circuit element. Wang and Ma constructed the fractional-order model of the Boost converter in continuous conduction mode (CCM) and discontinuous conduction mode (DCM) [19]; Yang and his colleagues proposed the fractional-order model of the BuckBoost converter in CCM [20], but no circuit simulations or experiments were presented to verify these models. In this paper, a fractional-order state-space averaging model of the Buck-Boost converter in pseudo-continuous conduction mode (PCCM) is established; numerical and circuit simulation experiments are presented to verify the efficiency of the proposed theoretical analysis.

Generally, Buck-Boost converters operate in CCM or DCM. In recent reports, pseudo-continuous conduction mode (PCCM) is proposed which is the third operation mode. Comparing with operating in DCM, in PCCM, the current handling capability of the converter is improved and the current ripple and voltage ripple are reduced. And a single-pole behavior in the control-to-output transfer function is exhibited; the load transient response is much faster than operating in CCM and DCM [21-23]. Therefore, the study of the fractional-order model of the Buck-Boost converter in PCCM is an important theoretical issue and has practical engineering value.

In this paper, we established the fractional-order statespace averaging model of the Buck-Boost converter in PCCM and analyzed the influence of orders on some dynamical properties of the fractional-order model. The rest of this paper is organized as follows: Section 2 is the preliminaries; some basic concepts of fractional calculus and the basic fractional-order inductor and capacitor models are introduced. In Section 3, based on fractional calculus, we established a fractional-order state-space averaging model of the Buck-Boost converter in PCCM. In Section 4, the quiescent operation point and transfer functions of the fractional-order converter are analyzed. Orders of the fractional-order model are proved to be extra parameters and have influence on the performance of the converter. In Section 5, numerical and circuit simulation experiments are implemented to verify the correctness of theoretical analysis and the proposed fractional-order model. Finally, in Section 6, influences of orders on the fractional-order model are summarized.

\section{Preliminaries}

2.1. Fractional Calculus. Fractional calculus allows operations of ordinary differentiations and integrations to noninteger-order. It is a generalization of traditional calculus, but its applicability is much wider [24]. The fundamental operator ${ }_{a} D_{t}^{\alpha}$, where $\alpha(\alpha \in \mathbb{R})$ is the order and $a$ and $t$ are the bounds of the operation, is defined as

$$
{ }_{a} D_{t}^{\alpha}= \begin{cases}\frac{d^{\alpha}}{d t^{\alpha}}, & \alpha>0 \\ 1, & \alpha=0 \\ \int_{a}^{t}(d \tau)^{-\alpha}, & \alpha<0 .\end{cases}
$$

The three best known definitions for fractional calculus are Grünwald-Letnikov (GL) definition, Riemann-Liouville (RL) definition, and Caputo definition [2].

Caputo definition is defined as

$$
{ }_{a} D_{t}^{\alpha} f(t)=\frac{1}{\Gamma(n-\alpha)} \int_{a}^{t} \frac{f^{(n)}(\tau)}{(t-\tau)^{\alpha-n+1}} d \tau,
$$

where $\Gamma(\cdot)$ is the Gamma function and $n \in N$ is the first integer which is not less than $\alpha, n-1<\alpha<n$.

The Laplace transform of Caputo fractional derivative satisfies

$$
\begin{aligned}
L\left\{{ }_{a} D_{t}^{\alpha} f(t)\right\}=s^{\alpha} F(s)-\sum_{k=0}^{n-1} s^{\alpha-k-1} f^{(m)}(0), & \\
& n-1<\alpha<n .
\end{aligned}
$$

For zero initial conditions, the Laplace transform of fractional derivatives has the following form:

$$
L\left\{{ }_{a} D_{t}^{\alpha} f(t)\right\}=s^{\alpha} F(s) .
$$

Theoretical calculations are based on the Caputo derivative and more specifically on the initial condition $x(0)$. Hartley and Lorenzo discuss the error incurred in using the Caputo-derivative Laplace transform [25]. It is now well established that more precisely initial state of a Fractional Differential Equation can be represented by the weighted integral of $z(w, 0)$ [26-30]. Nevertheless, under the premise that the error is acceptable, and for convenience, the Caputo derivative and the initial condition $x(0)$ are adopted.

2.2. The Fractional-Order Model of Capacitors and Inductors. The fractional-order model of capacitors stems from Curie's empirical law which is proposed in 1889 [13]:

$$
i(t)=\frac{V_{0}}{h_{1} t^{m}}, \quad 0<m<1,
$$

where $h_{1}$ is a constant related to the capacitance and the kind of the dielectric. $m$ is a constant close to 1 , related to the losses of the capacitor. $V_{0}$ is the DC voltage applied at $t=0$. 


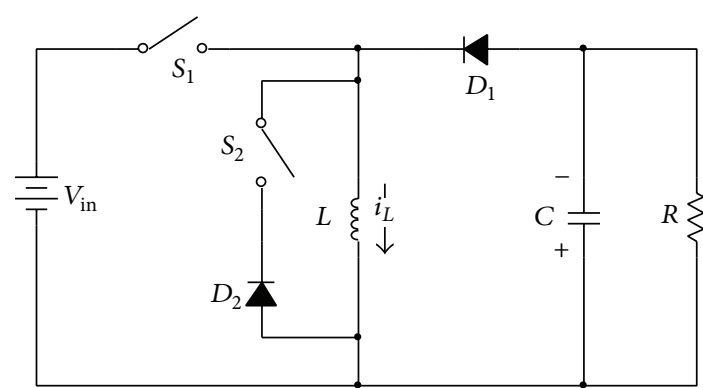

Figure 1: Buck-Boost converter in PCCM.

In 1994, based on fractional calculus, Westerlund and Ekstam developed a new capacitor theory [13]:

$$
i(t)=C_{f} \frac{d^{\beta} u(t)}{d t^{\beta}}, \quad 0<\beta<1,
$$

where $C_{f}$ is the capacitance of the capacitor related to the kind of dielectric. And $\beta$ is the order related to the losses of the capacitor. Westerlund and Ekstam provided various capacitor dielectrics with appropriated order $\beta$ by experiment.

Westerlund also created the fractional-order model of inductors [14]:

$$
u(t)=L_{f} \frac{d^{\alpha} i(t)}{d t^{\alpha}}, \quad 0<\alpha<1,
$$

where $L_{f}$ is the inductance of the inductor and $\alpha$ is the order related to the proximity effect.

In engineering applications, orders of capacitors and inductors are close to 1 [13]. In order to ensure that the power electronic devices can work properly, we redefine a fractional order between 0.95 and 1 .

\section{The State-Space Averaging Model of the Fractional-Order Buck-Boost Converter in PCCM}

3.1. The Fractional-Order Mathematical Model of the BuckBoost Converter. The Buck-Boost converter can operate as Buck (for voltage stepdown) or Boost (for voltage stepup) converter, inverting the voltage polarity. Connecting an inductor in parallel with a power switch makes the converter operate in PCCM [31]. The circuit diagram is shown in Figure 1. There are two fully controlled switching devices $S_{1}$ and $S_{2}$, two diodes $D_{1}$ and $D_{2}$, one DC input voltage $V_{\text {in }}$, one load resistor $R$, and two fractional-order energy storage elements $L$ and $C$ in the circuit.

In Figure 2, where $T$ is the switching time period, $T_{\text {on }}$ is the on time, $T_{\text {off }}$ is the off time for the switch, and $d_{1}+d_{2}+d_{3}$ $=1$. There are three states for the pseudo-continuous mode.

State 1. When $0<t \leq d_{1} T$, the circuit topology is shown in Figure 3. Switch $S_{1}$ is on, $S_{2}$ is off, and diodes $D_{1,2}$ are reversebiased. The inductor current $i_{L}$ rises.

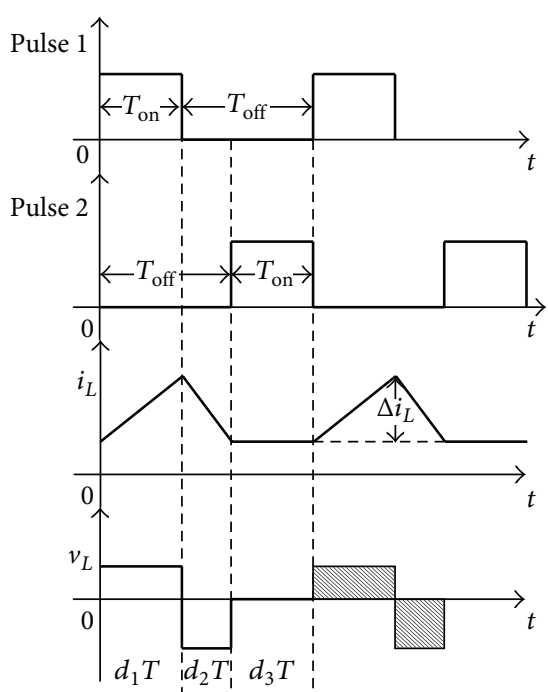

FIGURE 2: Inductor voltage and current of Buck-Boost converter in PCCM.

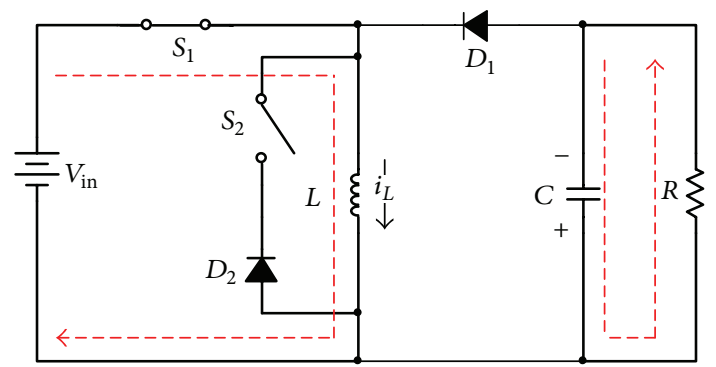

FIGURE 3: Schematic diagram of Buck-Boost converter in State 1.

The expression of the fractional-order mathematical model is

$$
\left[\begin{array}{c}
\frac{d^{\alpha} i_{L}(t)}{d t^{\alpha}} \\
\frac{d^{\beta} v_{C}(t)}{d t^{\beta}}
\end{array}\right]=\left[\begin{array}{cc}
0 & 0 \\
0 & -\frac{1}{C R}
\end{array}\right]\left[\begin{array}{c}
i_{L}(t) \\
v_{C}(t)
\end{array}\right]+\left[\begin{array}{c}
\frac{1}{L} \\
0
\end{array}\right] v_{\text {in }}(t) .
$$

State 2. When $d_{1} T<t \leq\left(d_{1}+d_{2}\right) T$, as shown in Figure 4, switches $S_{1,2}$ and diode $D_{2}$ are off and diode $D_{1}$ is forwardbiased and behaves as a short circuit; the inductor current $i_{L}$ ramps down.

The expression of the fractional-order mathematical model is

$$
\left[\begin{array}{c}
\frac{d^{\alpha} i_{L}(t)}{d t^{\alpha}} \\
\frac{d^{\beta} v_{C}(t)}{d t^{\beta}}
\end{array}\right]=\left[\begin{array}{cc}
0 & \frac{1}{L} \\
-\frac{1}{C} & -\frac{1}{C R}
\end{array}\right]\left[\begin{array}{l}
i_{L}(t) \\
v_{C}(t)
\end{array}\right]+\left[\begin{array}{l}
0 \\
0
\end{array}\right] v_{\text {in }}(t)
$$

State 3. When $\left(d_{1}+d_{2}\right) T<t \leq T$, switch $S_{1}$ and diode $D_{1}$ are off, switch $S_{2}$ and diode $D_{2}$ are on, and the inductor current $i_{L}$ maintains a constant theoretically. The circuit topology is shown in Figure 5. 


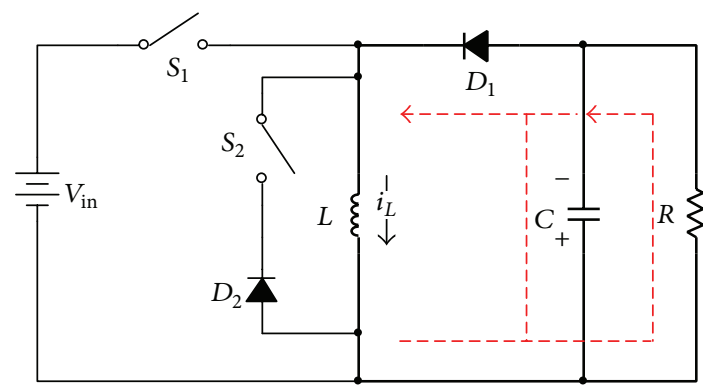

FIgURE 4: Schematic diagram of Buck-Boost converter in State 2.

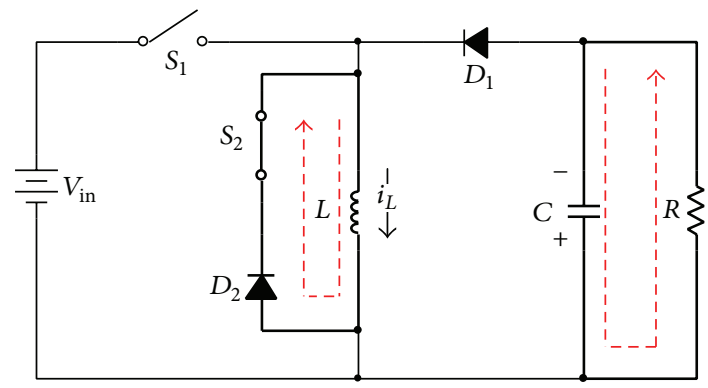

FIGURE 5: Schematic diagram of Buck-Boost converter in State 3.

The expression of the fractional-order mathematical model is

$$
\left[\begin{array}{c}
\frac{d^{\alpha} i_{L}(t)}{d t^{\alpha}} \\
\frac{d^{\beta} v_{C}(t)}{d t^{\beta}}
\end{array}\right]=\left[\begin{array}{cc}
0 & 0 \\
0 & -\frac{1}{C R}
\end{array}\right]\left[\begin{array}{l}
i_{L}(t) \\
v_{C}(t)
\end{array}\right]+\left[\begin{array}{l}
0 \\
0
\end{array}\right] v_{\text {in }}(t) .
$$

As shown in (8), (9), and (10), the inductor order $\alpha$ and the capacitor order $\beta$ can be considered as extra parameters of the fractional-order mathematical models in PCCM. The influence of these extra parameters on the performance of the converter will be discussed in the next section.

3.2. The Fractional-Order State-Space Averaging Model of the Buck-Boost DC/DC Converter. To remove the switching harmonics, waveforms over one switching period should be averaged [32]. The average value of variable $x(t)$ which is an arbitrary circuit variable of the Buck-Boost converter in one switching period is defined as follows:

$$
\langle x(t)\rangle_{T}=\frac{1}{T} \int_{t}^{t+T} x(\tau) d \tau .
$$

Its fractional-order form is

$$
\begin{aligned}
\frac{d^{\alpha}\langle x(t)\rangle_{T}}{d t^{\alpha}} & =\frac{d^{\alpha}\left((1 / T) \int_{t}^{t+T} x(\tau) d \tau\right)}{d t^{\alpha}} \\
& =\frac{1}{T} \int_{t}^{t+T}\left(\frac{d^{\alpha} x(\tau)}{d \tau^{\alpha}}\right) d \tau=\left\langle\frac{d^{\alpha} x(t)}{d t^{\alpha}}\right\rangle,
\end{aligned}
$$

where $\alpha$ is the order and $0.95<\alpha<1$.
Let us consider the fractional-order state-space averaging model of Buck-Boost converter in PCCM:

$$
\begin{aligned}
{\left[\begin{array}{c}
\frac{d^{\alpha}\left\langle i_{L}(t)\right\rangle_{T}}{d t^{\alpha}} \\
\frac{d^{\beta}\left\langle v_{C}(t)\right\rangle_{T}}{d t^{\beta}}
\end{array}\right]=} & {\left[\begin{array}{cc}
0 & \frac{d_{2}(t)}{L} \\
-\frac{d_{2}(t)}{C} & -\frac{1}{C R}
\end{array}\right]\left[\begin{array}{c}
\left\langle i_{L}(t)\right\rangle_{T} \\
\left\langle v_{C}(t)\right\rangle_{T}
\end{array}\right] } \\
& +\left[\begin{array}{c}
\frac{d_{1}(t)}{L} \\
0
\end{array}\right]\left\langle v_{\text {in }}(t)\right\rangle_{T} .
\end{aligned}
$$

Average values of circuit variables are defined as the following form:

$$
\begin{aligned}
\left\langle i_{L}(t)\right\rangle_{T} & =I_{L}+\widehat{i}_{L}(t), \\
\left\langle v_{C}(t)\right\rangle_{T} & =V_{C}+\widehat{v}_{C}(t), \\
\left\langle v_{\text {in }}(t)\right\rangle_{T} & =V_{\text {in }}+\widehat{v}_{\text {in }}(t), \\
d_{1}(t) & =D_{1}+\widehat{d}_{1}(t), \\
d_{2}(t) & =D_{2}+\widehat{d}_{2}(t),
\end{aligned}
$$

where variables in capital letters represent DC components and variables with the symbol “へ” above them represent AC components which are much smaller in magnitude than the corresponding DC component.

Equation (13) can be rewritten as

$$
\begin{aligned}
& {\left[\begin{array}{c}
\frac{d^{\alpha} I_{L}}{d t^{\alpha}}+\frac{d^{\alpha} \hat{i}_{L}(t)}{d t^{\alpha}} \\
\frac{d^{\beta} V_{C}}{d t^{\beta}}+\frac{d^{\beta} \widehat{v}_{C}(t)}{d t^{\beta}}
\end{array}\right]} \\
& =\left[\begin{array}{cc}
0 & \frac{D_{2}+\widehat{d}_{2}(t)}{L} \\
-\frac{D_{2}+\widehat{d}_{2}(t)}{C} & -\frac{1}{C R}
\end{array}\right]\left[\begin{array}{c}
I_{L}+\widehat{i}_{L}(t) \\
V_{C}+\widehat{v}_{C}(t)
\end{array}\right] \\
& +\left[\begin{array}{c}
\frac{D_{1}+\widehat{d}_{1}(t)}{L} \\
0
\end{array}\right]\left(V_{\text {in }}+\widehat{v}_{\text {in }}(t)\right) .
\end{aligned}
$$

DC components in (15) are as follows:

$$
\left[\begin{array}{c}
\frac{d^{\alpha} I_{L}}{d t^{\alpha}} \\
\frac{d^{\beta} V_{C}}{d t^{\beta}}
\end{array}\right]=\left[\begin{array}{cc}
0 & \frac{D_{2}}{L} \\
-\frac{D_{2}}{C} & -\frac{1}{C R}
\end{array}\right]\left[\begin{array}{c}
I_{L} \\
V_{C}
\end{array}\right]+\left[\begin{array}{c}
\frac{D_{1}}{L} \\
0
\end{array}\right] V_{\mathrm{in}} .
$$

The quiescent operation point is

$$
\left[\begin{array}{c}
I_{L} \\
V_{C}
\end{array}\right]=-\left[\begin{array}{cc}
0 & \frac{D_{2}}{L} \\
-\frac{D_{2}}{C} & -\frac{1}{C R}
\end{array}\right]^{-1}\left[\begin{array}{c}
\frac{D}{L} \\
0
\end{array}\right] V_{\text {in }}=\left[\begin{array}{c}
\frac{V_{\text {in }} D_{1}}{D_{2}^{2} R} \\
-\frac{V_{\text {in }} D_{1}}{D_{2}}
\end{array}\right] .
$$

The voltage ratio is defined as follows:

$$
M=\frac{V_{C}}{V_{\text {in }}}=-\frac{D_{1}}{D_{2}} .
$$


AC components of (15) are

$$
\begin{aligned}
& {\left[\begin{array}{l}
\frac{d^{\alpha} \hat{i}_{L}(t)}{d t^{\alpha}} \\
\left.\frac{d^{\beta} \widehat{v}_{C}(t)}{d t^{\beta}}\right]
\end{array}\right.} \\
& =\left[\begin{array}{cc}
0 & \frac{D_{2}+\widehat{d}_{2}(t)}{L} \\
-\frac{D_{2}+\widehat{d}_{2}(t)}{C} & -\frac{1}{C R}
\end{array}\right]\left[\begin{array}{l}
\hat{i}_{L}(t) \\
\widehat{v}_{C}(t)
\end{array}\right] \\
& +\left[\begin{array}{cc}
\frac{D_{1}+\hat{d}_{1}(t)}{L} \\
0
\end{array}\right] \widehat{v}_{\text {in }}(t) \\
& +\left[\begin{array}{cc}
0 & \frac{\widehat{d}_{2}(t)}{L} \\
-\frac{\widehat{d}_{2}(t)}{C} & 0
\end{array}\right]\left[\begin{array}{c}
I_{L} \\
V_{C}
\end{array}\right]+\left[\begin{array}{c}
\frac{\hat{d}_{1}(t)}{L} \\
0
\end{array}\right] V_{\text {in }},
\end{aligned}
$$

where $\widehat{d}_{2}(t) \widehat{i}_{L}(t), \widehat{d}_{2}(t) \widehat{v}_{C}(t)$, and $\widehat{d}_{1}(t) \widehat{v}_{\text {in }}(t)$ are high order small signal terms which can be omitted. Then the small signal AC equation of Buck-Boost converter in PCCM can be expressed as follows:

$$
\begin{aligned}
{\left[\begin{array}{c}
\frac{d^{\alpha} \hat{i}_{L}(t)}{d t^{\alpha}} \\
\frac{d^{\beta} \widehat{v}_{C}(t)}{d t^{\beta}}
\end{array}\right]=} & {\left[\begin{array}{cc}
0 & \frac{D_{2}}{L} \\
-\frac{D_{2}}{C} & -\frac{1}{C R}
\end{array}\right]\left[\begin{array}{c}
\hat{i}_{L}(t) \\
\widehat{v}_{C}(t)
\end{array}\right] } \\
& +\left[\begin{array}{c}
\frac{D_{1}}{L} \\
0
\end{array}\right] \widehat{v}_{\text {in }}(t) \\
& +\left[\begin{array}{cc}
0 & \frac{1}{L} \\
-\frac{1}{C} & 0
\end{array}\right]\left[\begin{array}{c}
I_{L} \\
V_{C}
\end{array}\right] \widehat{d}_{2}(t) \\
& +\left[\begin{array}{c}
\frac{1}{L} \\
0
\end{array}\right] V_{\text {in }} \hat{d}(t) .
\end{aligned}
$$

\section{Performance Analysis of the Fractional-Order Model of the Buck-Boost Converter in PCCM}

In this section, the quiescent operation point and transfer functions of the AC small signal model will be analyzed, because they have practical significance for the designing of various parameters and reflect the performance of the converter.

The inductor current ripple and output voltage ripple of the fractional-order Buck-Boost converter in PCCM are shown in Figure 6.

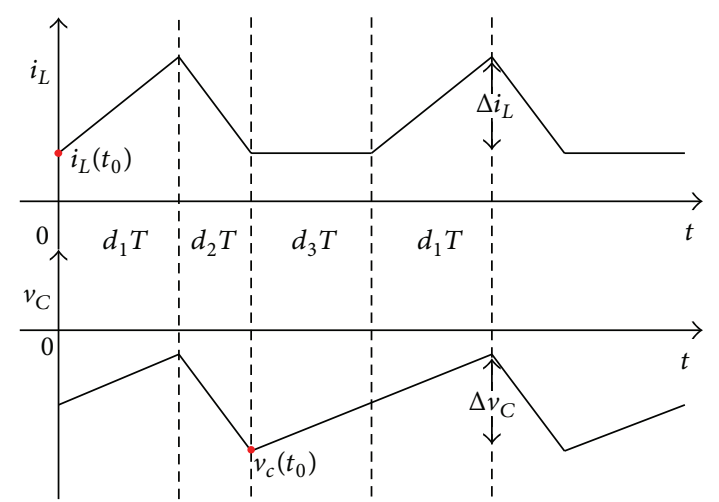

FIGURE 6: The inductor current ripple and output voltage ripple.

The small ripple approximation is defined as replacing waveforms with their low-frequency averaged values:

$$
\frac{d^{\alpha} i_{L}(t)}{d t^{\alpha}} \approx \frac{\left\langle v_{\text {in }}(t)\right\rangle_{T}}{L} .
$$

Using Caputo definition, we can get the corresponding initial condition as

$$
D^{k} i_{L}(0)=i_{L 0}^{(k)}, \quad k=0,1, \ldots, m-1 .
$$

Solving fractional-order differential equation (21), we can get

$$
\begin{aligned}
i_{L}(t)= & \frac{1}{\Gamma(\alpha)} \int_{0}^{t}(t-\tau)^{\alpha-1} \frac{\left\langle v_{\text {in }}(t)\right\rangle_{T}}{L} d \tau \\
& +\sum_{k=0}^{m-1} \frac{t^{k}}{k !} i_{L 0}^{(k)}(t) .
\end{aligned}
$$

In PCCM, the initial value of inductor current is given as $i_{L}\left(t_{0}\right)=i_{L \min }$

Then

$$
i_{L \max }=i_{L}\left(d_{1} T\right)=\frac{V_{\text {in }}\left(D_{1} T\right)^{\alpha}}{L \Gamma(\alpha) \alpha}+i_{L \min } .
$$

The inductor current ripple is

$$
\Delta i_{L}=\frac{V_{\text {in }}\left(D_{1} T\right)^{\alpha}}{L \Gamma(\alpha) \alpha} .
$$

The maximum and minimum values of inductor current are

$$
\begin{aligned}
& i_{L \max }=I_{L}+\frac{1}{2} \Delta i_{L}=\frac{V_{\text {in }} D_{1}}{D_{2}^{2} R}+\frac{V_{\text {in }}\left(D_{1} T\right)^{\alpha}}{2 L \Gamma(\alpha) \alpha}, \\
& i_{L \text { min }}=I_{L}-\frac{1}{2} \Delta i_{L}=\frac{V_{\text {in }} D_{1}}{D_{2}^{2} R}-\frac{V_{\text {in }}\left(D_{1} T\right)^{\alpha}}{2 L \Gamma(\alpha) \alpha} .
\end{aligned}
$$

According to Adomian decomposition scheme, one can get

$$
\frac{d^{\beta} x(t)}{d t^{\beta}}=A x(t)+f(x)
$$


In States 2 and 3, the load is powered by the capacitor. The output voltage of the converter is negative which satisfies the state equation and the amplitude is monotone decreasing:

$$
\frac{d^{\beta} v_{C}(t)}{d t^{\beta}}=-\frac{v_{C}(t)}{C R},
$$

where $A=-1 / C R, f(x)=0$, and $0.95<\beta<1$.

The solution of $(28)$ is

$$
v_{C}(t)=E_{\beta, 1}\left(A t^{\beta}\right) V_{\max },
$$

where $V_{\max }$ is the initial value of $v_{C}(t)$, which means $v_{C}\left(t_{0}\right)=$ $V_{\text {max }}$ for $t_{0}=0$.

When $t=\left(d_{1}+d_{3}\right) T$, the output voltage is

$$
v_{C}\left(\left(d_{3}+d_{1}\right) T\right)=V_{\max } E_{\beta, 1}\left(-\frac{\left(\left(d_{3}+d_{1}\right) T\right)^{\beta}}{R C}\right) .
$$

The variation of the output voltage is

$$
\Delta v=V_{\max }\left(1-E_{\beta, 1}\left(-\frac{\left(\left(d_{3}+d_{1}\right) T\right)^{\beta}}{R C}\right)\right) .
$$

According to (17) and (31), it yields

$$
\begin{aligned}
V_{\max }= & V_{C}+\frac{1}{2} \Delta v \\
= & \frac{V_{\mathrm{in}} D_{1}}{D_{2}} \\
& +\frac{V_{\max }}{2}\left(1-E_{\beta, 1}\left(-\frac{\left(\left(d_{3}+d_{1}\right) T\right)^{\beta}}{R C}\right)\right) \\
= & \frac{2 V_{\mathrm{in}} D_{1}}{D_{2}\left(1+E_{\beta, 1}\left(-\left(\left(d_{3}+d_{1}\right) T\right)^{\beta} / R C\right)\right)} .
\end{aligned}
$$

Taking (32) to (31) yields

$$
\Delta v=\frac{2 V_{\mathrm{in}} D_{1}\left(1-E_{\beta, 1}\left(-\left(\left(d_{3}+d_{1}\right) T\right)^{\beta} / R C\right)\right)}{D_{2}\left(1+E_{\beta, 1}\left(-\left(\left(d_{3}+d_{1}\right) T\right)^{\beta} / R C\right)\right)} .
$$

We can find from (25) and (33) that the inductor current ripple and the output voltage ripple are closely related to the order of energy storage elements. The ripple increases with the decreasing of the order.

Under conditions of zero initial value, the Laplace transform of converter equations is

$$
\begin{aligned}
& s^{\beta} \widehat{v}_{C}(s)=-\frac{D_{2} \hat{i}_{L}(s)}{C}-\frac{I_{L} \widehat{d}_{2}(s)}{C}-\frac{\widehat{v}_{C}(s)}{C R}, \\
& s^{\alpha} \widehat{i}_{L}(s)=\frac{D_{1} \widehat{v}_{\text {in }}(s)+V_{\text {in }} \widehat{d}_{1}(s)+D_{2} \widehat{v}_{C}(s)+V_{C} \widehat{d}_{2}(s)}{L} .
\end{aligned}
$$

Set the duty cycle variation to be zero:

$$
\begin{aligned}
& \widehat{d}_{1}(s)=0, \\
& \widehat{d}_{2}(s)=0 .
\end{aligned}
$$

According to (34), one can get the $v_{\text {in }}-$ to $-v_{C}$ and the $v_{\text {in }}{ }^{-}$ to $-i_{L}$ transfer function as follows:

$$
\begin{aligned}
G_{v_{\mathrm{C}} v_{\mathrm{in}}}(s) & =\left.\frac{\widehat{v}_{C}(s)}{\widehat{v}_{\text {in }}(s)}\right|_{\widehat{d}_{1}(s)=0, \widehat{d}_{2}(s)=0} \\
& =-\frac{D_{1} / D_{2}}{\left(L C / D_{2}^{2}\right) s^{\alpha+\beta}+\left(L / R D_{2}^{2}\right) s^{\alpha}+1}, \\
G_{i_{L} v_{\text {in }}}(s) & =\left.\frac{\widehat{i}_{L}(s)}{\widehat{v}_{\text {in }}(s)}\right|_{\widehat{d}_{1}(s)=0, \widehat{d}_{2}(s)=0} \\
& =\frac{\left(D_{1} / R D_{2}^{2}\right)\left(C R s^{\beta}+1\right)}{\left(L C / D_{2}^{2}\right) s^{\alpha+\beta}+\left(L / R D_{2}^{2}\right) s^{\alpha}+1} .
\end{aligned}
$$

Set the AC input voltage variation and the duty cycle $\widehat{d}_{2}$ to be zero:

$$
\begin{aligned}
& \widehat{v}_{\text {in }}(s)=0, \\
& \widehat{d}_{2}(s)=0 .
\end{aligned}
$$

The $\widehat{d}_{1}$-to- $v_{C}$ and the $\widehat{d}_{1}$-to- $i_{L}$ transfer functions are

$$
\begin{aligned}
G_{v_{C} d_{1}}(s) & =\left.\frac{\widehat{v}_{C}(s)}{\widehat{d}_{1}(s)}\right|_{\widehat{v}_{\text {in }}(s)=0, \widehat{d}_{2}(s)=0} \\
& =-\frac{V_{\text {in }} / D_{2}}{\left(L C / D_{2}^{2}\right) s^{\alpha+\beta}+\left(L / R D_{2}^{2}\right) s^{\alpha}+1}, \\
G_{i_{L} d_{1}}(s) & =\left.\frac{\widehat{i}_{L}(s)}{\widehat{d}_{1}(s)}\right|_{\widehat{v}_{\text {in }}(s)=0, \widehat{d}_{2}(s)=0} \\
& =\frac{\left(V_{\text {in }} / R D_{2}^{2}\right)\left(C R s^{\beta}+1\right)}{\left(L C / D_{2}^{2}\right) s^{\alpha+\beta}+\left(L / R D_{2}^{2}\right) s^{\alpha}+1} .
\end{aligned}
$$

Set the AC input voltage variation and the duty cycle $\widehat{d}_{1}$ to be zero:

$$
\begin{aligned}
& \widehat{v}_{\text {in }}(s)=0, \\
& \widehat{d}_{1}(s)=0 .
\end{aligned}
$$

According to (17) and (34), the $\widehat{d}_{2}$-to- $v_{C}$ and the $\widehat{d}_{2}$-to- $i_{L}$ transfer functions are

$$
\begin{aligned}
G_{v_{C} d_{2}}(s) & =\left.\frac{\widehat{v}_{C}(s)}{\widehat{d}_{2}(s)}\right|_{\widehat{v}_{\text {in }}(s)=0, \widehat{d}_{1}(s)=0} \\
& =-\frac{\left(V_{\text {in }} L D_{1} / D_{2}^{4} R\right) s^{\alpha}+V_{C} / D_{2}}{\left(L C / D_{2}^{2}\right) s^{\alpha+\beta}+\left(L / R D_{2}^{2}\right) s^{\alpha}+1}, \\
G_{i_{L} d_{2}}(s) & =\left.\frac{\widehat{i}_{L}(s)}{\widehat{d}_{2}(s)}\right|_{\widehat{v}_{\text {in }}(s)=0, \widehat{d}_{1}(s)=0} \\
& =-\frac{\left(V_{\text {in }} D_{1} / R D_{2}^{3}\right)\left(C R s^{\beta}+2\right)}{\left(L C / D_{2}^{2}\right) s^{\alpha+\beta}+\left(L / R D_{2}^{2}\right) s^{\alpha}+1} .
\end{aligned}
$$


TABLE 1: Parameters of the Buck-Boost converter.

\begin{tabular}{lcc}
\hline Parameter & Symbol & Value \\
\hline Input voltage & $V_{\text {in }}$ & $50 \mathrm{~V}$ \\
Capacitor & $C$ & $100 \mu \mathrm{F}$ \\
Inductance & $L$ & $1 \mathrm{mH}$ \\
Switching frequency & $f$ & $20 \mathrm{kHz}$ \\
Duty cycle & $D_{1}$ & 0.4 \\
Duty cycle & $D_{3}$ & 0.4 \\
The order & $\alpha$ & $0.95 / 1$ \\
The order & $\beta$ & $0.95 / 1$ \\
\hline
\end{tabular}

We can find from (36), (38), and (40) that orders of the inductor and capacitor have influence on transfer functions. That means fractional orders can be seen as extra parameters. When orders are 1, we can get integer-order transfer functions from the fractional-order model. The integer-order model is a special case of the fractional-order model.

\section{Experimental Researches}

In this section, some numerical and circuit simulation experiments are presented to verify the fractional-order model and the influence of the order on performances of the converter in PCCM. We choose 0.95 as the order which is close to 1 . Parameters of the Buck-Boost converter are listed in Table 1.

We select the load resistor as $R=20 \Omega$ to ensure that the converter is operating in PCCM. Difference values of the quiescent operating point between the integer-order and fractional-order Buck-Boost converter model are shown in Table 2.

In Table 2, we can find that the output voltage ripple and the inductor ripple rise with the decreasing of the order. That means the order of the Buck-Boost converter impacts the output characteristics of the converter obviously.

5.1. Numerical Simulation. In numerical simulation, Oustaloup's recursive approximation is adopted [33]. The switching frequency of the converter is selected as $f=20 \mathrm{kHz}$, the corresponding rotational frequency is $\omega=2 \pi f=1.256 \times$ $10^{5}$, and parameters of Oustaloup are $\omega_{h}=2 \times 10^{5}, \omega_{b}=$ $5 \times 10^{-6}$, and $N=6$.

Figure 7 shows the inductor current; the detailed values are listed in Table 3. We can see that, in the inductor current ripple, maximum and minimum values of the inductor current increase significantly in the fractional-order model. That means the effect of the inductor order on the inductor current should be appropriately considered.

The order also influences the output voltage. As shown in Figure 8 and Table 4, in the output voltage ripple, the maximum and minimum values of output voltage increase significantly in the fractional-order model.

5.2. Circuitry Simulation Experiment. To further verify the results of the theoretical analysis, the circuit simulation experiments are presented.

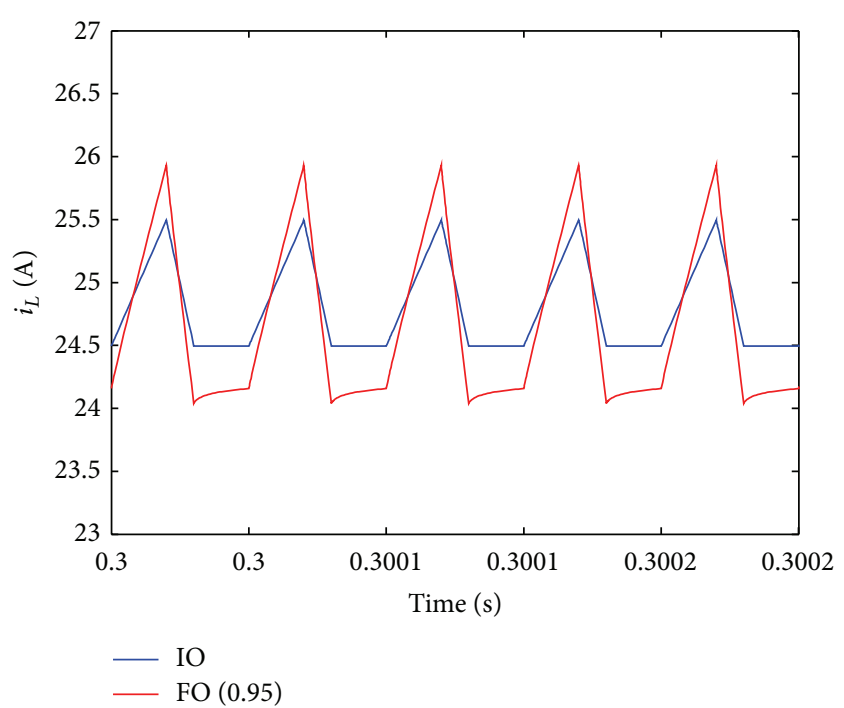

Figure 7: The inductor current.

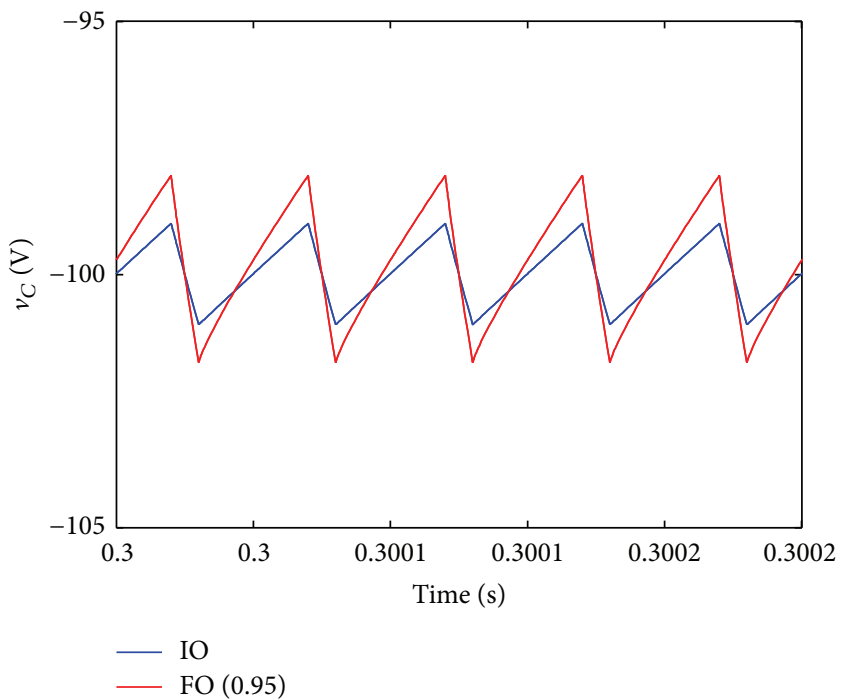

FIGURE 8: The output voltage.

By using resistor/capacitor or resistor/inductor networks, we can construct an approximation circuit of the fractionalorder circuit elements. We choose the chain structure as the fractance unit to approximately achieve the fractional-order circuit elements.

The chain fractance unit of fractional-order capacitor is shown in Figure 9.

The transfer function model of the capacitor is

$$
H(s)=R_{\text {in }}+\sum_{k=1}^{n} \frac{1 / C_{k}}{\left(s+1 / R_{k} C_{k}\right)} .
$$

We choose $\beta=0.95, C=100 \mu \mathrm{F}$, and $n=6$. We can calculate resistors and inductors in Figure 9 by the method of undetermined coefficients, comparing the input 
TABLE 2: The quiescent operating point of the Buck-Boost DC/DC converter.

\begin{tabular}{lccc}
\hline Parameter & Symbol & Integer order & Fractional order $(0.95)$ \\
\hline Output voltage & $V_{C}$ & $-100 \mathrm{~V}$ & $-100 \mathrm{~V}$ \\
Output voltage ripple & $\Delta v_{C}$ & $2 \mathrm{~V}$ & $3.38 \mathrm{~V}$ \\
Minimum values of the output voltage & $v_{C \min }$ & $-101 \mathrm{~V}$ & $-101.69 \mathrm{~V}$ \\
Maximum values of the output voltage & $v_{C \max }$ & $-99 \mathrm{~V}$ & $-98.31 \mathrm{~V}$ \\
Inductor current & $I_{L}$ & $25 \mathrm{~A}$ & $25 \mathrm{~A}$ \\
Inductor current ripple & $\Delta i_{L}$ & $1 \mathrm{~A}$ & $1.75 \mathrm{~A}$ \\
Minimum values of the inductor current & $i_{L \min }$ & $24.5 \mathrm{~A}$ & $24.12 \mathrm{~A}$ \\
Maximum values of the inductor current & $i_{L \max }$ & $25.5 \mathrm{~A}$ & $25.88 \mathrm{~A}$ \\
\hline
\end{tabular}

TABLE 3: Values of inductor current.

\begin{tabular}{lccc}
\hline Order of the model & Inductor current ripple & Minimum values of the inductor current & Maximum values of the inductor current \\
\hline 1 & $\Delta i_{L}=1 \mathrm{~A}$ & $i_{L \min }=24.5 \mathrm{~A}$ & $i_{L \max }=25.5 \mathrm{~A}$ \\
0.95 & $\Delta i_{L}=1.89 \mathrm{~A}$ & $i_{L \min }=24.04 \mathrm{~A}$ & $i_{L \max }=25.93 \mathrm{~A}$ \\
\hline
\end{tabular}

TABLE 4: Values of the output voltage.

\begin{tabular}{lccc}
\hline Order of the model & Output voltage ripple & Minimum values of the output voltage & Maximum values of the output voltage \\
\hline 1 & $\Delta v_{C}=1.96 \mathrm{~V}$ & $v_{C \text { min }}=-100.9 \mathrm{~V}$ & $v_{C \max }=-98.96 \mathrm{~V}$ \\
0.95 & $\Delta v_{C}=3.66 \mathrm{~V}$ & $v_{C \min }=-101.7 \mathrm{~V}$ & $v_{C \max }=-98.04 \mathrm{~V}$ \\
\hline
\end{tabular}

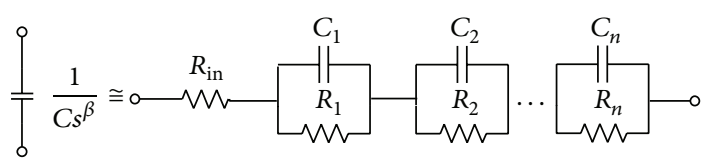

FIGURE 9: The approximate circuit of the fractional-order capacitor $(C=100 \mu \mathrm{F}, \beta=0.95)$.

impedance of the approximate circuit model and Oustaloup's approximation:

$$
\frac{1}{C} s^{-\beta}=R_{\mathrm{in}}+\sum_{k=1}^{n} \frac{1 / C_{k}}{\left(s+1 / R_{k} C_{k}\right)} .
$$

Solving (42), parameters of the chain fractance unit of fractional-order capacitor are as follows: $R_{1}=0.036 \Omega, R_{2}=$ $2.9 \Omega, R_{3}=230.64 \Omega, R_{4}=18.32 \mathrm{k} \Omega, R_{5}=1.46 \mathrm{M} \Omega$, $R_{6}=1.11 \times 10^{3} \mathrm{M} \Omega, R_{\text {in }}=2.2 \mathrm{~m} \Omega, C_{1}=246.27 \mu \mathrm{F}, C_{2}=$ $306.98 \mu \mathrm{F}, C_{3}=386.42 \mu \mathrm{F}, C_{4}=484.48 \mu \mathrm{F}, C_{5}=612.41 \mu \mathrm{F}$, and $C_{6}=158.58 \mu \mathrm{F}$.

Bode diagrams of the fractional-order capacitor by numerical simulations and circuit simulations are compared in Figure 10; they are approximate fitting.

The chain fractance unit of fractional-order inductor is shown in Figure 11.

The transfer function model of the inductor is

$$
H(s)=\frac{1}{\sum_{k=1}^{n}\left(\left(1 / L_{k}\right) /\left(s+R_{k} / L_{k}\right)+1 / R_{\mathrm{in}}\right)} .
$$

We choose $\alpha=0.95, L=1 \mathrm{mH}$, and $n=6$. We can calculate resistors and inductors in Figure 11 by the method of undetermined coefficients, comparing the input
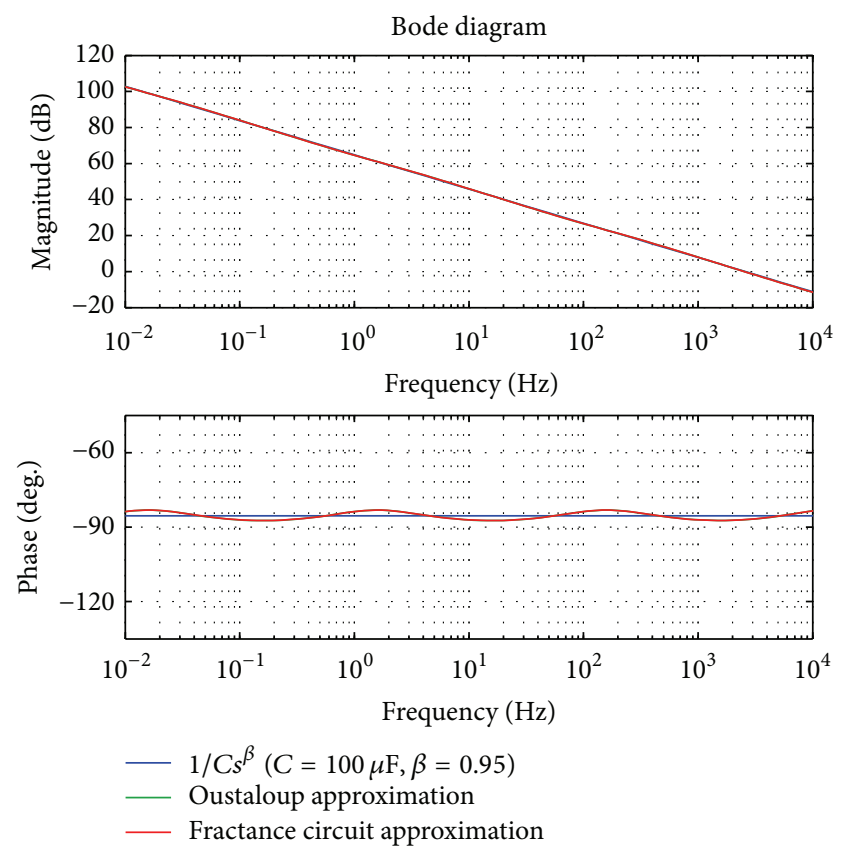

Figure 10: The Bode diagram of the 0.95 -order capacitor.

impedance of the approximate circuit model and Oustaloup's approximation:

$$
\frac{1}{L} s^{-\alpha}=\sum_{k=1}^{n} \frac{1 / L_{k}}{\left(s+R_{k} / L_{k}\right)}+\frac{1}{R_{\mathrm{in}}} .
$$

Parameters of the chain fractance unit of the fractionalorder capacitor are as follows: $R_{1}=276.32 \Omega, R_{2}=3.44 \Omega$, 


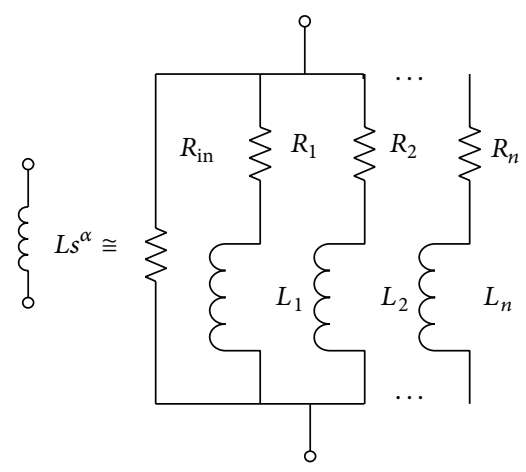

FIGURE 11: The approximate circuit of the fractional-order inductor $(L=1 \mathrm{mH}, \alpha=0.95)$.
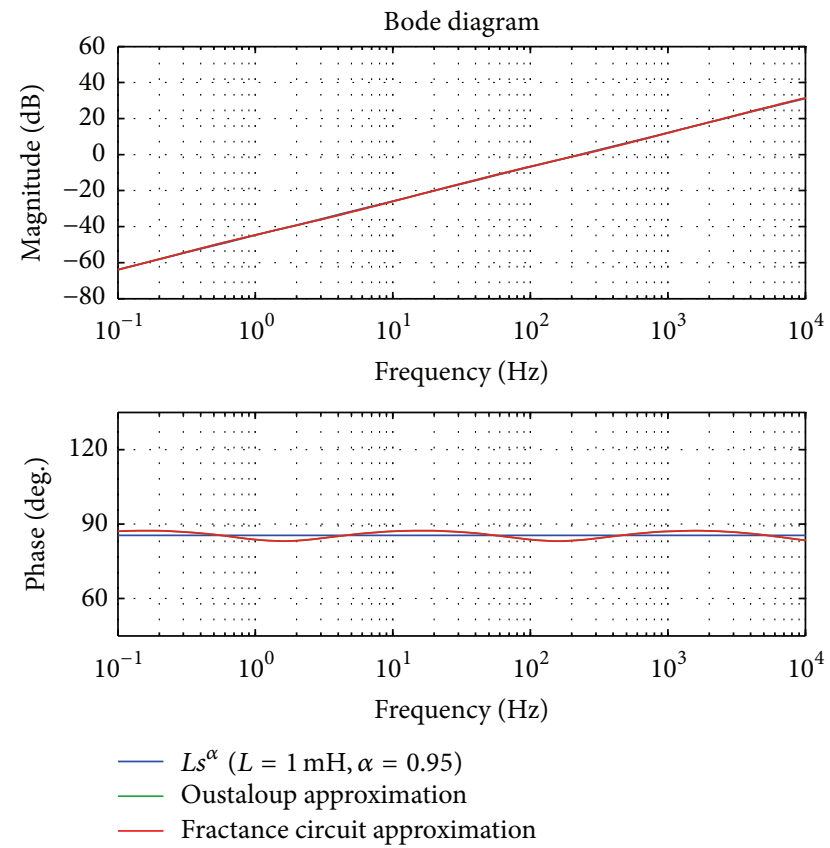

FIGURE 12: The Bode diagram of the 0.95 -order inductor.

$R_{3}=43.4 \mathrm{~m} \Omega, R_{4}=545.84 \mu \Omega, R_{5}=6.87 \mu \Omega, R_{6}=8.98 \times$ $10^{-3} \mu \Omega, R_{\text {in }}=2.2 \mathrm{~m} \Omega, L_{1}=2.5 \mathrm{mH}, L_{2}=3.1 \mathrm{mH}, L_{3}=$ $3.9 \mathrm{mH}, L_{4}=4.9 \mathrm{mH}, L_{5}=6.1 \mathrm{mH}$, and $L_{6}=1.6 \mathrm{mH}$.

Bode diagrams of the fractional-order capacitor by numerical simulations and circuit simulations are compared in Figure 12; they are approximate fitting. Psim.

In Figure 13, we implemented the circuit simulation by

The load resistor is selected as $R=20 \Omega$; due to nonideal circuit elements, the output voltage and inductor current are slightly different from the numerical simulation. As shown in Figures 14 and 15, with the decrease of the order of energy storage elements, the response of the converter becomes faster and the overshoot becomes smaller.

All circuit simulation experiments are consistent with results of the theoretical analysis and numerical simulations. The influence of the fractional order on the performance

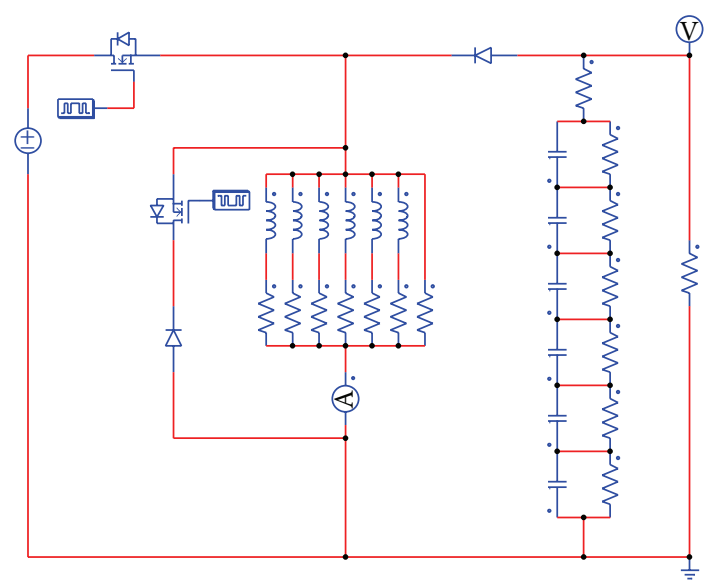

Figure 13: The 0.95-order Buck-Boost converter by Psim.

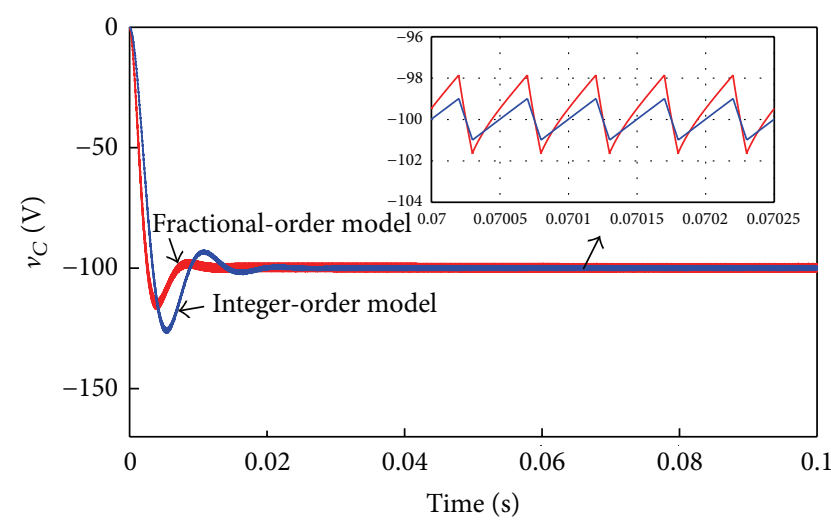

FIgURE 14: The output voltage.

of the converter is obvious; that means the order should be considered as extra parameters.

\section{Conclusions}

Fractional-order models can increase the flexibility and degrees of freedom by means of fractional parameters. They are discussed in many fields and generate some new concepts. In this paper, based on fractional calculus, we established the fractional-order state-space averaging model of the BuckBoost converter in PCCM. And some influences of the order on the quiescent operating point and the low-frequency characteristics of the converter are investigated by theoretical analyses and numerical and circuit simulations. We have proved that fractional components increase the two ripples (the output voltage ripple $\Delta v_{C}$ and the inductor current ripple $\left.\Delta i_{L}\right)$, but with the decrease of the order of energy storage elements, the response of the converter becomes faster and the overshoot becomes smaller. In theory, all the actual energy storage elements should be fractional order. That may be an important reason why the actual device is always imperfect. Therefore, how to determine the order of energy storage elements and the relationship between the fractional 


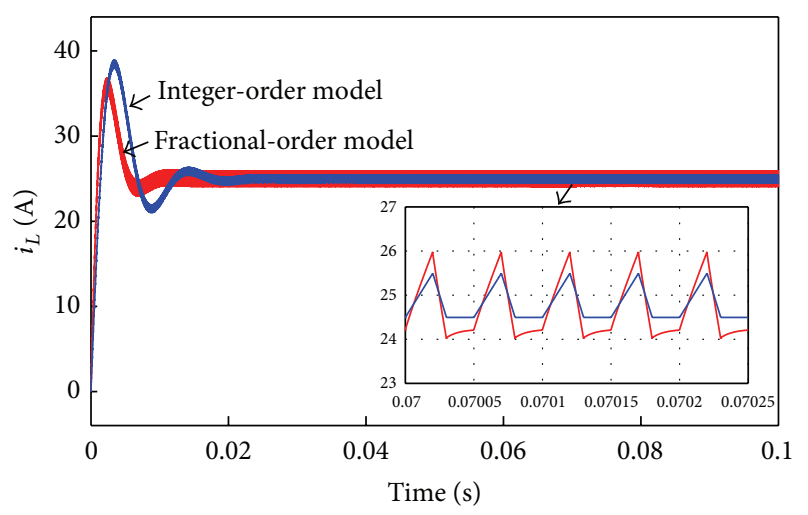

FIgURE 15: The inductor current.

order and performances of the actual energy storage elements are our future research directions.

\section{Conflict of Interests}

The authors declare that there is no conflict of interests regarding the publication of this paper.

\section{Acknowledgments}

This work was supported by the National Natural Science Foundation of China (Grant nos. 51507134, 51177117, and 51279161), Scientific Research Program Funded by Shaanxi Provincial Education Department (Program no. 15JK1537), and Doctoral Scientific Research Foundation of Xi'an Polytechnic University (Grant no. BS15025).

\section{References}

[1] K. B. Oldham and J. Spanier, The Fractional Calculus, Academic Press, New York, NY, USA, 1974.

[2] I. Podlubny, Fractional Differential Equations, Academic Press, San Diego, Calif, USA, 1999.

[3] I. S. Jesus and J. A. T. Machado, "Development of fractional order capacitors based on electrolyte processes," Nonlinear Dynamics, vol. 56, no. 1-2, pp. 45-55, 2009.

[4] F.-Q. Wang and X.-K. Ma, "Transfer function modeling and analysis of the open-loop Buck converter using the fractional calculus," Chinese Physics B, vol. 22, no. 3, Article ID 030506, 2013.

[5] A. Jalloul, J.-C. Trigeassou, K. Jelassi, and P. Melchior, "Fractional order modeling of rotor skin effect in induction machines," Nonlinear Dynamics, vol. 73, no. 1-2, pp. 801-813, 2013.

[6] I. Petráš, "Chaos in the fractional-order Volta's system: modeling and simulation," Nonlinear Dynamics, vol. 57, no. 1-2, pp. 157-170, 2009.

[7] S. I. R. Arias, D. R. Muñoz, J. S. Moreno, S. Cardoso, R. Ferreira, and P. J. P. Freitas, "Fractional modeling of the AC largesignal frequency response in magnetoresistive current sensors," Sensors, vol. 13, no. 12, pp. 17516-17533, 2013.
[8] A. Charef, "Modeling and analog realization of the fundamental linear fractional order differential equation," Nonlinear Dynamics, vol. 46, no. 1-2, pp. 195-210, 2006.

[9] F. Q. Wang and X. K. Ma, "Modeling and analysis of the fractional order Buck converter in DCM operation by using fractional calculus and the circuit-averaging technique," Journal of Power Electronics, vol. 13, no. 6, pp. 1008-1015, 2013.

[10] A. G. Radwan and M. E. Fouda, "Optimization of fractionalorder RLC filters," Circuits, Systems, and Signal Processing, vol. 32, no. 5, pp. 2097-2118, 2013.

[11] I. Podlubny, "Fractional-order systems and PI-lambda-D-mucontrollers," IEEE Transactions on Automatic Control, vol. 44, no. 1, pp. 208-214, 1999.

[12] I. Petráš, "Chaos in fractional-order population model," International Journal of Bifurcation and Chaos, vol. 22, no. 4, Article ID 1250072, 2012.

[13] S. Westerlund and L. Ekstam, "Capacitor theory," IEEE Transactions on Dielectrics and Electrical Insulation, vol. 1, no. 5, pp. 826-839, 1994.

[14] S. Westerlund, Dead Matter has Memory!, Causal Consulting, Kalmar, Sweden, 2002.

[15] J. A. T. Machado and A. M. S. F. Galhano, "Fractional order inductive phenomena based on the skin effect," Nonlinear Dynamics, vol. 68, no. 1-2, pp. 107-115, 2012.

[16] T. C. Haba, G. Ablart, T. Camps, and F. Olivie, "Influence of the electrical parameters on the input impedance of a fractal structure realised on silicon," Chaos, Solitons \& Fractals, vol. 24, no. 2, pp. 479-490, 2005.

[17] T. C. Haba, G. L. Loum, and G. Ablart, "An analytical expression for the input impedance of a fractal tree obtained by a microelectronical process and experimental measurements of its nonintegral dimension," Chaos, Solitons \& Fractals, vol. 33, no. 2, pp. 364-373, 2007.

[18] R. Martinez, Y. Bolea, A. Grau, and H. Martinez, "Fractional DC/DC converter in solar-powered electrical generation systems," in Proceedings of the IEEE Conference on Emerging Technologies \& Factory Automation (ETFA '09), pp. 1-6, Mallorca, Spain, September 2009.

[19] F.-Q. Wang and X.-K. Ma, "Fractional order modeling and simulation analysis of Boost converter in continuous conduction mode operation," Acta Physica Sinica, vol. 60, no. 7, Article ID 070506, 2011.

[20] N.-N. Yang, C.-X. Liu, and C.-J. Wu, "Modeling and dynamics analysis of the fractional-order Buck-Boost converter in continuous conduction mode," Chinese Physics B, vol. 21, no. 8, Article ID 080503, 2012.

[21] D. Ma and W.-H. Ki, "Fast-transient PCCM switching converter with freewheel switching control," IEEE Transactions on Circuits and Systems II: Express Briefs, vol. 54, no. 9, pp. 825-829, 2007.

[22] F. Zhang and J. P. Xu, "A novel PCCM boost PFC converter with fast dynamic response," IEEE Transactions on Industrial Electronics, vol. 58, no. 9, pp. 4207-4216, 2011.

[23] Y. Yang, L. Sun, and X. B. Wu, "A single-inductor dualoutput buck converter with self-adapted PCCM method," in Proceedings of the IEEE International Conference of Electron Devices and Solid-State Circuits (Edssc '09), pp. 87-90, Xi'an, China, December 2009.

[24] I. Petras, Fractional Order Nonlinear Systems-Modeling, Analysis and Simulation, Springer, New York, NY, USA, 2011.

[25] T. T. Hartley and C. F. Lorenzo, "The error incurred in using the caputo-derivative laplace-transform," in Proceedings of the 
ASME International Design Engineering Technical Conferences and Computers and Information in Engineering Conference, vol. 4, pp. 271-278, San Diego, Calif, USA, September 2009.

[26] J. Sabatier, M. Merveillaut, R. Malti, and A. Oustaloup, "How to impose physically coherent initial conditions to a fractional system?" Communications in Nonlinear Science and Numerical Simulation, vol. 15, no. 5, pp. 1318-1326, 2010.

[27] J. C. Trigeassou, N. Maamri, J. Sabatier, and A. Oustaloup, "State variables and transients of fractional order differential systems," Computers \& Mathematics with Applications, vol. 64, no. 10, pp. 3117-3140, 2012.

[28] T. T. Hartley, R. J. Veillette, J. L. Adams, and C. F. Lorenzo, "Energy storage and loss in fractional-order circuit elements," IET Circuits Devices \& Systems, vol. 9, no. 3, pp. 227-235, 2015.

[29] T. T. Hartley, R. J. Veillette, C. F. Lorenzo, and J. L. Adams, "On the energy stored in fractional-order electrical elements," in Proceedings of the ASME International Design Engineering Technical Conferences and Computers and Information in Engineering Conference, 2013, vol. 4, ASME, 2014.

[30] T. T. Hartley, C. F. Lorenzo, J.-C. Trigeassou, and N. Maamri, "Equivalence of history-function based and infinitedimensional-state initializations for fractional-order operators," Journal of Computational and Nonlinear Dynamics, vol. 8, no. 4, Article ID 041014, 2013.

[31] D. S. Ma, W.-H. Ki, and C.-Y. Tsui, "A pseudo-CCM/DCM SIMO switching converter with freewheel switching," IEEE Journal of Solid-State Circuits, vol. 38, no. 6, pp. 1007-1014, 2003.

[32] R. W. Erickson, Fundamentals of Power Electronics, Chapman and Hall, New York, NY, USA, 1997.

[33] A. Oustaloup, F. Levron, B. Mathieu, and F. M. Nanot, "Frequency-band complex noninteger differentiator: characterization and synthesis," IEEE Transactions on Circuits and Systems I: Fundamental Theory and Applications, vol. 47, no. 1, pp. 25-39, 2000. 


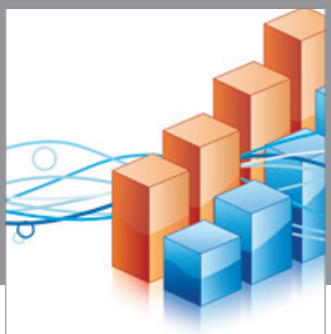

Advances in

Operations Research

vatem alat4

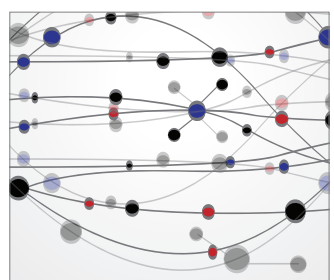

\section{The Scientific} World Journal
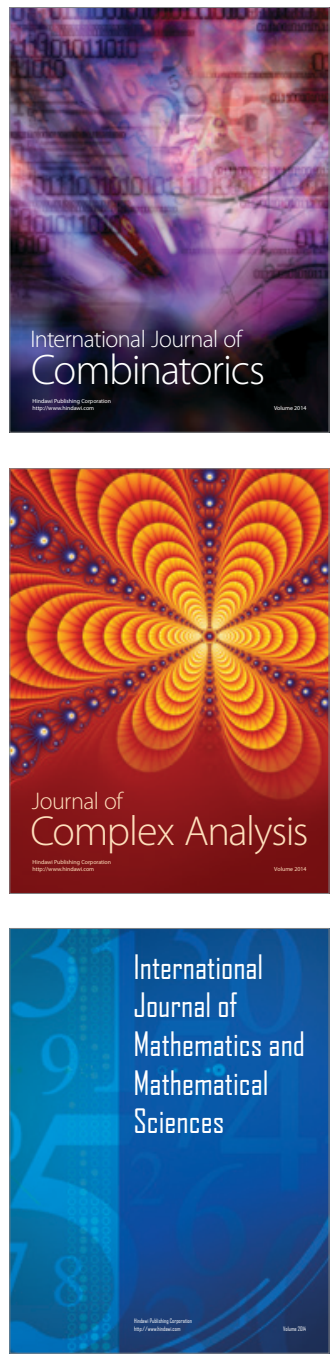
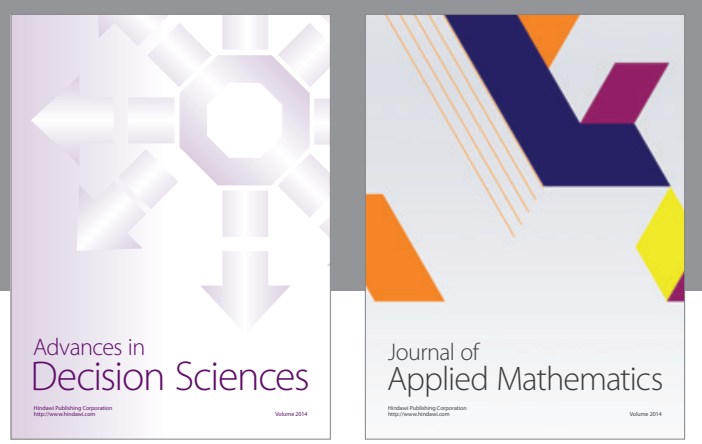

Algebra

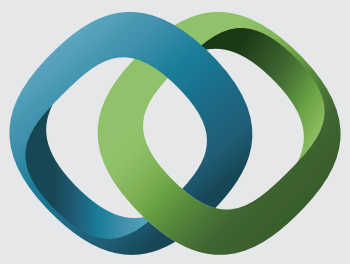

\section{Hindawi}

Submit your manuscripts at

http://www.hindawi.com
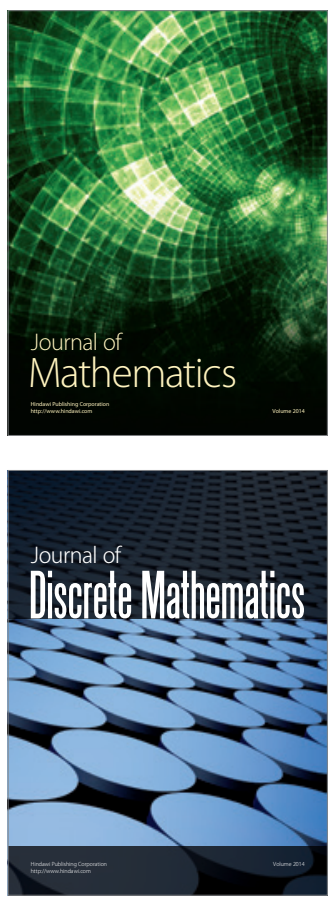

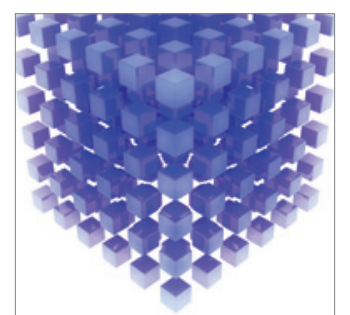

Mathematical Problems in Engineering
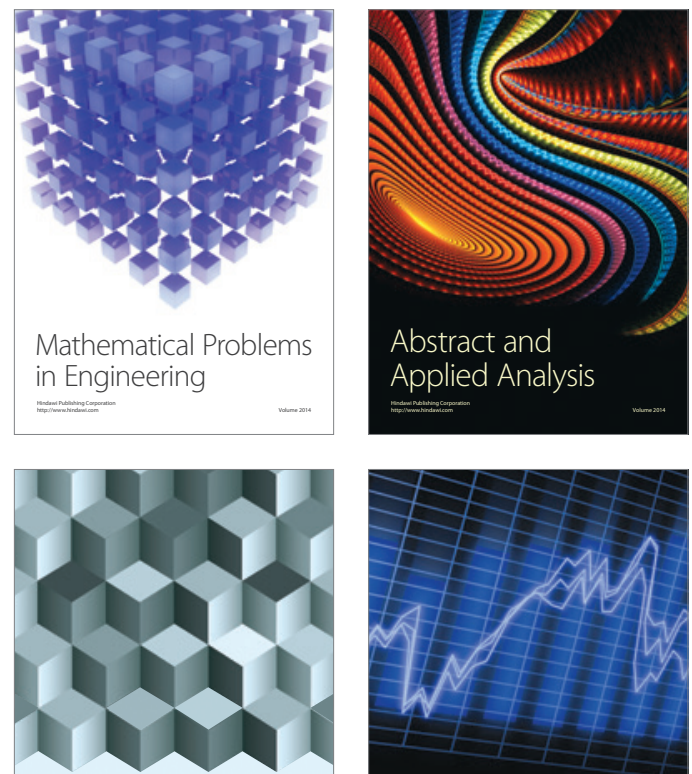

Journal of

Function Spaces

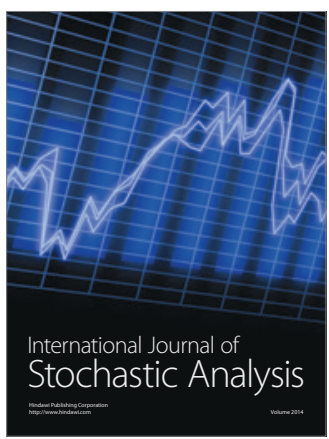

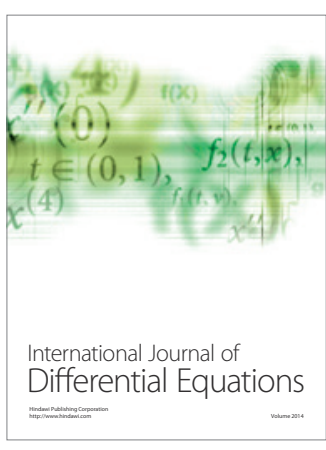
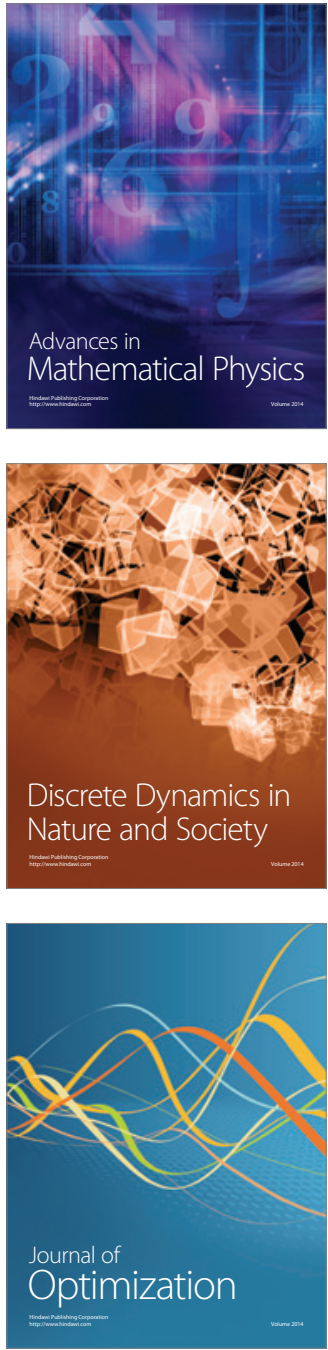